East African Medical Journal Vol. 77 No. 2 February 2000

ONCHOCERCIASIS IN GILGEL GHIBE RIVER VALLEY SOUTH WEST ETHIOPIA.

A. Taye, MSc, Department of Biology, T. Gebre-Michael, PhD, Institute of Pathobiology, Addis Ababa University, P. O. Box 1176, Addis Ababa, Ethiopia and S. Taticheff, $\mathrm{PhD}$, Ethiopian Health and Nutrition Research Institute, P.O. Box 1242, Addis Ababa, Ethiopia.

Request for reprints to: Dr. T. Gebre-Michael P.O. Box 1176, Addis Ababa, Ethiopia.

\title{
ONCHOCERCIASIS IN GILGEL GHIBE RIVER VALLEY SOUTHWEST ETHIOPIA.
}

\author{
A. TAYE, T. GEBRE-MICHAEL and S. TATICHEFF
}

\begin{abstract}
Objective: To determine the prevalence of onchocerciasis and the entomological transmission indices such as the parous rate and annual transmission potential (ATP).

Setting: Gilgel Ghibe village, Gilgel Ghibe River Valley Southwest Ethiopia between April 1994 and March 1995.

Subjects: Two hundred twenty eight subjects of the total 400 population in Gilgel Ghibe village were subjected to parasitological and clinical examinations.

Method: Two skin snips per person were taken and examined for microfilariae of Onchocerca volvulus. Fly collections were done from dawn to dusk from human baits seated in pairs at four representative sites at the river bank and away from the river bank. Flies were dissected for parity and infections with $O$. volvulus larvae.

Results: Among the 228 people examined, the prevalence of the disease was low $(17 \%)$, being higher in males (19\%) than in females (14\%). The geometric mean of microfilarial density was 11.1 (range, 1-132) mf per skin snip. Itching followed by pigmentary changes were the most common clinical signs and symptoms. The predominant anthropophilic blackfly species was Simulium (Edwardsellum) damnosum s.l. The annual parous rate and ATP were $\mathbf{7 4 . 7 \%}$ and 1669.5, respectively, being higher at the river bank than at sites further away suggesting a greater risk of infection by the river side.

Conclusion: The low prevalence of onchocerciasis in Gilgel Ghibe areavis-a-vis the high ATP level could be due to the possible presence of bovine onchocerciasis in the area. Further studies employing molecular techniques are thus required to identify $O$. volvulus from other filariae in flies.
\end{abstract}

\section{INTRODUCTION}

Onchocerciasis is widespread in western Ethiopia stretching from the Takazi valley in the northwest (Humera lowlands) to the Omo valley in the southwest in varying levels of endemicity which range from $17-84 \%(1-7)$. The prevailing clinical picture of the disease in Ethiopia includes various degrees of skin changes. Eye lesions and blindness due to the disease appear to be absent or uncommon.

Previous clinico-epidemiological investigations(13,5-7) or entomological studies of the disease (8-10) in Ethiopia were conducted independent of each other and often in different foci. Entomological and epidemiological studies have neither been conducted simultaneously nor followed one other in one focus. As a result, the relationship between the entomological data and the pattern of disease in different foci and ecological areas of Ethiopia is not fully understood. For example, Gebre-Michael(9), GebreMichael and Gemetchu(10) estimated very high annual transmission potentials (ATP) of 3567, 5478 and 1963 for Simulium (Edwardsellum) damnosum Theobald s.l. in Ghibe, Gilgel Ghibe and Gojeb river valleys, respectively.
These suggested very high prevalences and intensities of the disease in these areas similar to those seen in forest and savannah villages in West Africa $(11,12)$. However, the corresponding parasitological and clinical data in the above areas were not determined and the above high transmission indices could not be related to the clinicoparasitological patterns.

The present study was therefore conducted to determine the prevalence and intensity of onchocerciasis in one of the above areas (Gilgel Ghibe river valley) and its association with entomological data determined simultaneously.

\section{MATERIALS AND METHODS}

Study area: The study area has already been described in detail(10). Briefly, there is a small 'village' (Gilgel Ghibe) located $320 \mathrm{~km}$ south-west of Addis Ababa at 1700 metres above sea level in the Ghibe River Valley. It lies just by the bridge on the Gilgel Ghibe river comprising of about 400 inhabitants (1994 census by 'kebele' - the local administrative office). The inhabitants of this village mainly work in a sawmill factory by the river bank and supplement their earnings with farming, raising cattle, and small scale trading. 
Parasitological and clinical study: The total population of the village of 400 was targeted for the parasitological and clinical study. For this purpose, the 'Kebele' office was approached to ensure that every individual above the age of one year was included in the survey.

For the parasitological examination, two skin snips, one from each side of the buttocks were taken using an entomological needle and half of a razor blade which had previously been cleaned with alcohol and heat-sterilised over a spirit lamp flame. Each skin snip was placed in separate wells of a microtitre plate containing $100 \mu \mathrm{l}$ of normal saline. The plate was then covered with an adhesive plaster and incubated for 24 hours at room temperature. After 24 hours, the suspension was pipetted and the wells were washed to release those microfilariae which were adherent to the plate or to the skin snip. The suspensions and the washing were examined on slides for microfilariae under the $10 \mathrm{x}$ objective of a compound microscope. When microfilariae were detected, they were counted with a tally counter and expressed as the average of the two skin snips per person.

Information on clinical symptoms of the disease and history of residence in the area were also obtained from each subject.

Entomological study: Collection of adult blackflies were made at four sites thought to be 'representative' for the village. Site 1 was at the river bank while sites 2, 3 and 4 were at distances of $150 \mathrm{~m}, 300 \mathrm{~m}$ and $400 \mathrm{~m}$, respectively, away from the river bank and inwards to the village. A twelve-hour (0600 to 1800 hours) collection of flies landing on a pair of human baits/ collectors was conducted at each site every month from April 1994 to March 1995. Six young adults who were found to be skin snip positive were selected from the study population to serve as fly baits/collectors. At each site, two baits/collectors worked for half a day to be replaced by another pair for the remaining catching session of the day. The flies caught were immediately identified(13) and dissected for parity based on the examination of the ovaries(14). All parous flies were preserved in $80 \%$ alcohol, brought to the laboratory in Addis Ababa where they were stained in Mayer's acid haemalum and dissected for filarial infection and identification(10,15,16).

For each site, the annual biting rate (ABR), annual infective biting rate (AIBR) and annual transmission potential (ATP) based on $\mathrm{L}_{3}$ larvae found in the whole body were calculated as the sum of monthly biting rates and transmission potentials $(10,17)$. Furthermore, these transmission indices were estimated for Gilgel Ghibe village as a whole from pooled data of the four sites since it was thought to be a better estimate.

\section{RESULTS}

Parasitological and clinical data: Table 1 shows the results of skin snip examination for microfilariae of Onchocerca volvulus (Leuckart). An overall prevalence of $17.1 \%$ (39/228) was detected. The prevalence of infections in males was higher $(19 \%)$ than in females $(15 \%)$, although this difference was not significant ( $>0.05)$. In both sexes, maximum infection rate was observed in the age group 15-29, and the least in the age group 1-14.

The community microfilarial load as expressed by the geometric mean of microfilariae per skin snip was determined to be 11. 1 (Table 2). Males had a mean microfilarial load of 13.8 in comparison with 7.9 in females. Microfilarial count ranged from 1 to 132 per skin snip.

Of the 39 individuals with positive skin snips, only 22 $(56.4 \%)$ had typical signs and symptoms suggestive of onchocerciasis (Table 3 ). Itching and skin changes were the most common signs and symptoms of the disease. No

Table 1

Age and sex standardised prevalence of Onchocerca volvulus

\begin{tabular}{|c|c|c|c|c|c|c|}
\hline \multirow{2}{*}{$\begin{array}{l}\text { Age } \\
\text { Group } \\
\text { (yrs.) }\end{array}$} & \multicolumn{2}{|c|}{ Males } & \multicolumn{2}{|c|}{ Females } & \multicolumn{2}{|c|}{ Total } \\
\hline & $\begin{array}{l}\text { No. } \\
\text { Exam. }\end{array}$ & No. Pos. $(\%)$ & $\begin{array}{l}\text { No. } \\
\text { Exam. }\end{array}$ & $\begin{array}{l}\text { No. } \\
\text { Pos. }(\%)\end{array}$ & $\begin{array}{l}\text { No. } \\
\text { Exam. }\end{array}$ & $\begin{array}{l}\text { No. } \\
\text { Pos.(\%) }\end{array}$ \\
\hline $1-14$ & 48 & $2(4.2)$ & 36 & $1(2.8)$ & 84 & $3(3.6)$ \\
\hline $15-29$ & 25 & $9(36)$ & 38 & $9(23.7)$ & 63 & $18(28.6)$ \\
\hline $30-49$ & 40 & $10(25)$ & 22 & $4(18.2)$ & 62 & $14(22.6)$ \\
\hline$>50$ & 8 & $2(25)$ & 11 & $2(18.2)$ & 19 & $4(21.1)$ \\
\hline Total & 121 & 23(19) & 107 & $16(15)$ & 228 & $39(17.1)$ \\
\hline
\end{tabular}

Table 2

Microfilarial densities among infected individuals according to age and sex

\begin{tabular}{|c|c|c|c|c|c|c|}
\hline \multirow{2}{*}{$\begin{array}{l}\text { Age } \\
\text { group } \\
\text { (yrs.) }\end{array}$} & \multicolumn{2}{|c|}{ Males } & \multicolumn{2}{|c|}{ Females } & \multicolumn{2}{|c|}{ Total } \\
\hline & $\begin{array}{l}\text { Geom. } \\
\text { mean }\end{array}$ & Range & $\begin{array}{l}\text { Geom. } \\
\text { mean }\end{array}$ & Range & $\begin{array}{l}\text { Geom. } \\
\text { mean }\end{array}$ & Range \\
\hline $1-14$ & 15.9 & $4-37$ & 1 & 1 & 6.9 & $1-37$ \\
\hline $15-29$ & 17.0 & $2-68$ & 10.7 & $2-67$ & 13.5 & $2-68$ \\
\hline $30-49$ & 11.2 & $1-86$ & 2.9 & $1-13$ & 7.9 & $1-86$ \\
\hline$>50$ & 14.8 & $6-61$ & 21.4 & 4-132 & 17.8 & 4-132 \\
\hline Total & 13.8 & $1-86$ & 7.9 & $1-132$ & 11.1 & $1-132$ \\
\hline
\end{tabular}


nodules and visual impairments were detected in all the subjects examined. The remaining 17 (43.6\%) individuals of the positive cases had no signs and symptoms of the disease at all.

Entomological data: The composition of black fly populations caught on human baits at various sites is shown in Table 4. The predominant species was Simulium (Edwardsellum) damnosum s.l. (99.92\%) at all the sites. Simulium (Lewisellum) ethiopiense Fain and Oomen accounted for only $0.08 \%(n=5)$ of the total catch; all were caught at the river bank.

The results of dissections and the estimated transmission indices (ABRs, AIBRs and ATPs) of $S$. damnosum s.1. are summarised in Table 5. The number of flies caught and parous rates were higher at the river bank (Site 1 ) than at sites further away from the river bank (Sites 2-4). Thus, the highest parous rate $(87.5 \%)$ was recorded at the river bank and the lowest rate $(41.4 \%)$ was recorded at the furthest site from the river bank (Site 4). The overall parous rate was $74.7 \%$.

Developing larvae $\left(\mathrm{L}_{1} \& \mathrm{~L}_{2}\right)$ and third stage infective Onchocerca volvulus-like larvae $\left(\mathrm{L}_{3}\right)$ were isolated from S. damnosum s.l. of all sites (Table 5). Infection rates were generally higher at the river bank than at other sites. No filariae were recovered from the few $S$ ethiopiense collected and dissected ( $n$ parous $=3$ ).

Table 3

The frequency of onchocercal clinical signs and symptoms by age and sex and compared with those showing micriofilariae in skin snips (Numbers in parenthesis are individuals with skin snip positives)

\begin{tabular}{|c|c|c|c|c|c|c|c|c|c|c|c|c|}
\hline \multirow[t]{2}{*}{$\begin{array}{l}\text { Age } \\
\text { Group }\end{array}$} & \multicolumn{2}{|c|}{ Itching } & \multicolumn{2}{|c|}{$\begin{array}{c}\text { Pigmentary } \\
\text { changes }\end{array}$} & \multicolumn{2}{|c|}{$\begin{array}{l}\text { Papular } \\
\text { rash }\end{array}$} & \multicolumn{2}{|c|}{ Nodules } & \multicolumn{2}{|c|}{$\begin{array}{l}\text { Itching and } \\
\text { pigmentary } \\
\text { changes }\end{array}$} & \multicolumn{2}{|c|}{$\begin{array}{c}\text { Itching and } \\
\text { papular } \\
\text { rash }\end{array}$} \\
\hline & M & $\mathrm{F}$ & M & $\mathrm{F}$ & $\mathrm{M}$ & $\mathrm{F}$ & $\mathrm{M}$ & $\mathrm{F}$ & M & $\mathrm{F}$ & $\mathrm{M}$ & $\mathrm{F}$ \\
\hline $1-14$ & $5(2)$ & $1(0)$ & 0 & 0 & 0 & 0 & 0 & 0 & 0 & 0 & 0 & 0 \\
\hline $15-29$ & $6(2)$ & $8(2)$ & $2(0)$ & $1(0)$ & 0 & 0 & 0 & 0 & $2(2)$ & 0 & 0 & $2(2)$ \\
\hline $30-49$ & $14(1)$ & $5(4)$ & $3(1)$ & 0 & 0 & 0 & 0 & 0 & $4(3)$ & 0 & $1(1)$ & 0 \\
\hline$>50$ & $3(0)$ & 0 & 1(1) & (0) & 0 & 0 & 0 & 0 & 0 & $1(1)$ & 0 & 0 \\
\hline Total & $28(5)$ & $14(6)$ & $6(2)$ & $2(0)$ & 0 & 0 & 0 & 0 & $6(5)$ & $1(1)$ & $1(1)$ & $2(2)$ \\
\hline
\end{tabular}

Table 4

Number and species of anthropophilic black flies

\begin{tabular}{|c|c|c|c|c|}
\hline Site & $\begin{array}{c}\text { No. } \\
\text { Man-days }\end{array}$ & $\begin{array}{l}\text { No. } \\
\text { S. damnosum } \\
\text { (\% of total) }\end{array}$ & $\begin{array}{l}\text { No. } \\
\text { S. ethiopiense } \\
\text { (\% of total) }\end{array}$ & $\begin{array}{l}\text { Total } \\
\text { flies }\end{array}$ \\
\hline 1. & 24 & $3477(99.86)$ & $5(0.14)$ & 3482 \\
\hline 2. & 24 & 1935(100) & 0 & 1935 \\
\hline 3. & 24 & $909(100)$ & 0 & 909 \\
\hline 4. & 24 & $162(100)$ & 0 & 162 \\
\hline Total & 96 & $6483(99.92)$ & $5(0)$ & 6488 \\
\hline
\end{tabular}

Table 5

Dissection results of Simulium damnosum and the estimated annual biting rates and transmission potentials of the different sites. $($ ABR $=$ Annual biting rate; $A I B R=$ Annual infective biting rate; $A T P=$ Annual transmission potential. Estimates based on all L3 O. volvulus larvae found in any part of the fly body).

\begin{tabular}{|c|c|c|c|c|c|}
\hline Parameter (for the village) & Site 1 & Site 2 & Site 3 & Site 4 & Total \\
\hline Flies dissected & 3477 & 1935 & 909 & 162 & 6483 \\
\hline No. $(\%)$ parous & $\begin{array}{l}3052 \\
(87.5)\end{array}$ & $\begin{array}{l}1208 \\
(62.7)\end{array}$ & $\begin{array}{l}517 \\
(56.9)\end{array}$ & $\begin{array}{l}67 \\
(41.4)\end{array}$ & $\begin{array}{l}4844 \\
(74.7)\end{array}$ \\
\hline No. (\%) parous with L1\& L2 & 155 & 60 & 13 & 4 & 232 \\
\hline larvae & $(5.1)$ & $(4.9)$ & $(2.5)$ & $(5.9)$ & $(4.8)$ \\
\hline No. $(\%)$ parous with L3 O. & 71 & 9 & 5 & 2 & 87 \\
\hline volvulus larvae. & $(2.3)$ & $(0.7)$ & $(1.0)$ & $(3.0)$ & $(1.8)$ \\
\hline Total L3 O. volvulus larvae & 360 & 43 & 9 & 22 & 442 \\
\hline $\mathrm{ABR}$ & 53415.5 & 29776 & 14018 & 2501 & 24928.8 \\
\hline AIBR & 1067.2 & 275.4 & 77.5 & 31 & 328.7 \\
\hline ATP & 5409.5 & 8019 & 139.5 & 341 & 1669.5 \\
\hline
\end{tabular}


The ABR, AIBR and ATP were also consistently and significantly higher $(\mathrm{P}<0.001)$ at the river bank than at all the sites away from the river bank (Table 5). Pooling the data from the four sites, the estimated ABR, AIBR and ATP for Gilgel Ghibe village were 24929, 329 and 1669.5, respectively. These indices were much smaller than the estimates at the river bank alone, by factors of at least $\mathrm{x} 2$ to $\mathrm{x} 3$.

\section{DISCUSSION}

The present study shows that onchocerciasis is hypoendemic in Gilgel Ghibe village(18) and is similar to that reported from northwest Ethiopia(4) as well as to many foci in the southwest(1). Oomen(1) also found onchocerciasis to be of low endemicity in Asendabo, a village not far from the present study locality. The low microfilarial density and the mild clinical picture of the disease also point to a low prevalence and intensity of the disease in Gilgel Ghibe village.

The prevalence of the disease was found to be higher in males than females (though not statistically significant) suggesting males to be at a greater risk of infection. Male preponderance is consistent with other observations in Ethiopia(1, 5-7) and elsewhere(19,20).

As in the previous observation(10), the present study also revealed that the predominant species and the principal vector in Gilgel Ghibe area was Simulium damnosum s.l. Simulium ethiopiense was found to be very rare and its density seems to have declined drastically recently compared to previous reports from the same locality $(8,10)$. Similar trends, accompanied also by a decline in transmission of onchocerciasis have recently been observed in other members of the $S$. neavei Roubaud group in East Africa(21). This decline has largely been attributed to recent degradation of vegetation cover in the vicinity of their breeding sites. Generally, the $S$. neavei group is known to thrive best in heavily-forested riverine environments(22). It is also known that deforestation was the sole means used to eradicate S. neavei s.s. and onchocerciasis from some foci in Kenya(23).

The overall parous rate $(74 \%)$ of $S$. damnosum s.l in the present study was similar to those in the savannah areas of West Africa $(24,25)$. It was also noted that parous flies concentrated more by the river side, while nulliparous flies dispersed further away from the river side. The observed high parous rate by the river bank $(87.5 \%)$ in the present study is also similar to the previous record at the river side $(91.5 \%)$ in the same locality(10). This pattern of differential dispersal has been observed in S. damnosum s.l. in West African savannah(24, 25). The Gilgel Ghibe area is a typical savannah with little of the original primary vegetation confined to the riverside.

The ATP level (1669.5 larvae/man/year) estimated for the village in the present study was much smaller than the previous estimate (5478) in the same locality(10). This is due to the fact that all the fly collection sites in the previous study (10) were all located at the river bank.
These gave very high parous rates, consequently high fly infection rates and very high ATP. Considering the river bank alone (Site 1 ) of the present study, very high AIBR and ATP levels could be estimated (Table 5) to be similar to the previous AIBR (858) and ATP (5478) levels(10). It was also interesting to note that the ATP levels at sites further away from the river bank were remarkably lower compared to the river bank. It follows from this that persons who frequently visit the river for fishing, swimming and washing clothes. will be exposed to intense transmission than those who work and live further away from the river side.

The ATP level estimated for the whole village based on the four representative sites was still too high and could not explain the low prevalence of onchocerciasis in Gilgel Ghibe village. In the savannah and forest areas of west Africa, such ATP levels have been associated with high prevalence of the disease $(11,12)$. The reason for the discrepancy between the low prevalence of disease and high ATP level in the present study may be due to the zoophilic behaviour of $S$. damnosum s.l. and the possible existence of bovine Onchocerca spp. (e.g. O. ochengi Bwangamoi) in the area which have been shown to develop in S. damnosum s.l. and morphologically indistinguishable from $O$. volvulus $(26,27)$. Further studies may thus be required elsewhere in Ethiopia to see whether or not disease patterns could be related to entomological data. For the present, mass treatment with ivermectin may not be highly desirable in the Gilgel Ghibe area according to WHO criteria(28).

\section{ACKNOWLEDGEMENTS}

This work was supported by the Addis Ababa University research fund from the Swedish Agency for Research and Co-operation with developing countries (SAREC). The assistance of Messrs Assefa Aga and Tariku Belay (Jimma Institute of Health Sciences) is gratefully acknowledged.

\section{REFERENCES}

1. Oomen, A.P.Studies on Onchocerciasis and Elephantiasis in Ethiopia, De Erven, F. Bohr, N.V. Haarlem, 115pp., 1969.

2. Iwamoto, I., Tada, I. and Wonde, T. Clinical manifestations of onchocerciasis in endemic foci of Illubabor province, Ethiopia. Trop. Med. 1973; 15:36.

3. De Sole, G. and Walton, J.C. Onchocerciasis in Gemu Gofa: an anthropological and ecological survey. Ethiop. Med. J. 1976 14:37.

4. Zein, A.Z. The epidemiology of onchocerciasis in northwestern Ethiopia. Trop. geogr. Med. 1986; 38:33.

5. Tatichef, S., Abebe, M., Workineh, W. and Hana, N.G. Onchocerciasis: a prevalence study in Bebeka, Ethiopia. Trop. Med. Parasit. 1987 38:279.

6. Gundersen, S.G., Schmitt-Lechner, A. and Bjorvatn, B. Onchocerciasis in the Blue Nile of Western Ethiopia. Trans. roy. Soc. trop. Med. Hyg. 1988; 82:122.

7. Yeneneh, H., Mengistu, F. and Ayele, T.A. multidiciplinary study of onchocerciasis in Bure area, Ethiopia. Ethiop. Med. J. 1989; 27:121. 
8. White, G. B. Man-biting species of Chrysops Meigen, Culicoides Laterille and Simulium Laterille in Ethiopia, with discussion of their vector potentialities. Trans. roy. Soc. trop. Med. Hyg. 1977; 71: 161.

9. Gebre-Michael, T.Studies on the anthropophilic species of Simulium in the Ghibe river valley, unpublished M.Sc. dissertation, Addis Ababa University, 101pp., 1983.

10. Gebre-Michael, T. and Gemetchu, T. Anthropophilic blackflies(Diptera: Simuliidae) and onchocerciasis transmission in south-west Ethiopia. Med. Vet. Entomol. 1996; 10: 44.

11. Duke, B.D.L., Moore, P.J. and Anderson, J. Studies on factors influencing the transmission of onchocerciasis. VII. A comparison of the Onchocerca volvulus transmission potentials of Simulium damnosum populations in four Cameroon rain forest villages and the pattern of onchocerciasis associated herewith. Ann. trop. Med. Parasit. 1972; 66: 219.

12. Duke, B.D.L., Anderson, J. and Fuglsang, H. The Onchocerca volvulustransmission potentials and associated patterns of onchocerciasis at four Cameroon Sudan savannah villages. Tropenmed. Parasit. 1975; 26: 143.

13. Crosskey, R.W. Blackflies (Simuliidae). Medical Insects and Arachnids (eds. R.P. Lane and R.W. Crosskey), pp. 241, 1993. Chapman \& Hall, London.

14. W.H.O. Epidemiology of Onchocerciasis. Wld. Hlth. Org Tech. Rep. Ser. 1976; No. 597: 96pp.

15. Nelson, G.S. Staining of filarial larvae in insects before dissection. Bull. Wld. Hlth. Org 1958; 19:204.

16. Voelker, J. and Garms, R. Morphological studies of unknown filarial larvae.Animal Research and Development. Vol 5, pp 105-123. 1977. Institute for Scientific Cooperation, Tubingen.

17. WHO Expert Committee on Onchocerciasis. Wld. Hlth. Org. Tech. Rep. Ser. 1987; No. 752: 167pp.

18. WHO Expert Committee on Onchocerciasis. Wld. Hlth. Org. Tech. Rep. Ser. 1966; 335:94pp.

19. McMahon, J.P., Sowa, S.I.C., Maude, G.H. and Kirkwood,
B.R. Onchocerciasis in Sierra Leone 2: a comparison of forest and savannah villages. Trans. roy. Soc. trop. Med Hyg, 1988; 82: 595.

20. Porter, C.H., Collins, R.C. and Bennet, D.B. Vector density, parasite prevalence and transmission of Onchocerca volvulus in Guatemala.Amer. J. trop. Med. Hyg, 1988; 39: 567.

21 Garms, R., Yocha, J. and Kipp, W. Decline of Simulium neave $i$ and its associated crabs in the Onchocerciasis foci of the Ruwenzori area, West Uganda, during the past 20 years. Paper presented at the 16th Annual British Simulium Group Meeting, The Natural History Museum, London, 17th November, 1993.

22. McCrae, A.W.R. Ecology and speciation in African blackflies (Diptera: Simuliidae). Biol. J: Linn. Soc. 1969; 1: 43 .

23. McMahon, J.P., Highton, R.B. and Goiny, H. The eradication of Simulium neavei from Kenya. Bull. Wld. Hlth. Org. 1958; 19: 75.

24. Le Berre, R. Contribution a l'etude biologique deSimulium damnosum Theobald, 1903 (Diptera, Simuliidae). Mem. Off. Rech. Scient. Tech. Outre-mer. 1966; 17: 204.

25. Duke, B.O.L. The differential dispersal of nulliparous and parous Simulium domnosum. Tropenmed. Parasit. 1975; 26:88.

26. Wahl, G., Ekale, D., Enyong, P. and Renez, A. The development of Onchocerca dukei and O. ochengi microfilariae to infective stage larvae in Simulium damnosum s.l. and in members of the S. medusaeforme group, following intra-thoracic injection. Ann. Trop. Med. Parasit. 1991; 85: 329.

27. McCall, P.J., Townson, H. and Tress, A.J. Morphometric differentiation of Onchocerca volvulus and O. ochengi infective larvae.Trans. roy. Soc. trop. Med. Hyg, 1992; 86: 63.

28. WHO. Strategies for ivermectin distributions through primary health care systems. WHO/PBL/91. 1991; No. 24: $62 \mathrm{pp}$. 